\title{
Nuclear Medicine Procedures Do Not Pose Cancer Risks in Women-Unappreciated or Otherwise
}

\author{
Anat Biegon, Dinko Franceschi, and Mark Schweitzer \\ Department of Radiology, Stony Brook University School of Medicine, Stony Brook, New York
}

See the associated article on page 1489.

$\mathbf{I}_{\mathrm{n}}$

$\mathrm{n}$ an article in this issue of The Journal of Nuclear Medicine (1), Siegel et al. mount a passionate attack on the idea that low-dose diagnostic imaging is associated with increased risk of cancer; which they blame on the (mis)use of the linear no-threshold model of cancer attributable to radiation. Unfortunately, in their zeal to annihilate the linear no-threshold model, the authors completely ignore the context, contents, and message of our paper (2). Our paper focuses on the consistent failure to consider female physiology in procedures involving parenteral administration of radioactive compounds ("nuclear medicine procedures" in the title-not just low-dose radiation associated with diagnostic imaging addressed by the authors of the critique). Specifically, we focus on the importance of the menstrual cycle in determining radiation dose to female reproductive organs. We clearly distinguish, rather than "conflate," potential risks associated with research on, diagnostic use of, and therapeutic use of injected radiopharmaceuticals. In the discussion of diagnostic imaging, we do state that the cancer risks are largely hypothetical but that this is not the case for targeted radionuclide therapy.

The reviewed literature points to large menstrual-cycle-related fluctuations in the rate of processes (cell division, glucose metabolism) and concentration of molecular species (e.g., enzymes and receptors) targeted by nuclear medicine procedures, which, in the very few instances where the issue was investigated directly, translate into fold difference in tracer uptake and order of magnitude differences in organ dose $(3,4)$.

Regardless of where one stands on the linear no-threshold model, we are all expected to uphold the principle of ALARA (as low as reasonably achievable $(5,6)$ ). In the context of nuclear medicine, the purpose would be to keep radiation dose to organs, calculated from dosimetry studies, as low as reasonably achievable. However, historically, most dosimetry studies did not include women, and the newer ones that do, fail to consider the hormonal status of the women included. This is predicated on the "conventional wisdom" assuming organ dose data from men can be used to predict organ dose in women, and that organ dose from women can be generalized across hormonal states (menopause, different stages of the cycle). Simply put, unless we change the way dosimetry studies are performed, we will continue to lack the most basic evidence to support dosing guidelines in women for

Received Sep. 7, 2018; revision accepted Sep. 8, 2018.

For correspondence or reprints contact: Anat Biegon, Stony Brook University School of Medicine, 101 Nicolls Rd., Stony Brook, NY 11794.

E-mail: anat.biegon@stonybrook.edu

Published online Sep. 13, 2018.

COPYRIGHT (c) 2018 by the Society of Nuclear Medicine and Molecular Imaging. DOI: 10.2967/jnumed.118.218834 radiopharmaceuticals, including those currently used and the large number of new ones being developed for targeted radionuclide therapy, where the risk of organ damage and secondary cancer is clear.

The authors also take issue with our statement that nuclear medicine lacks tools to reduce unnecessary exposure to reproductive organs when compared with procedures using external radiation. What should have been obvious is we were referring to targeting and volume reduction (7). Thus, a head CT or brain irradiation does not expose reproductive organs to radiation, but any nuclear medicine procedure exposes all organs regardless of the location of the target. We do propose that performing nuclear medicine procedures during the least susceptible phase of the menstrual cycle (which needs to be determined for each agent by dosimetry) might be a simple way to reduce unnecessary exposure, health risks, nondiagnostic scans, and false-positive findings in reproductive organs of young women. Tellingly, to avoid the latter, this approach has been widely adopted for breast MRI scans $(8,9)$. We strongly suggest it is high time our field attempts to respond to the challenge of considering sex as a biologic factor (10), especially in view of the excess risk of radiation-induced solid tumors in young women relative to men, repeatedly documented in the largest available epidemiological studies (11).

\section{DISCLOSURE}

No potential conflict of interest relevant to this article was reported.

\section{REFERENCES}

1. Siegel JA, Greenspan B, Silberstein EB, Sacks B, Marcus CS, Stabin MG. Nuclear medicine procedures do not pose cancer risks in women-unappreciated or otherwise. J Nucl Med. 2018;59:1489-1490.

2. Biegon A, Franceschi D, Schweitzer ME. Nuclear medicine procedures in women: unappreciated risks to reproductive organs? Radiology. July 10, 2018 [Epub ahead of print].

3. Lerman H, Metser U, Grisaru D, Fishman A, Lievshitz G, Even-Sapir E. Normal and abnormal ${ }^{18} \mathrm{~F}$-FDG endometrial and ovarian uptake in pre- and postmenopausal patients: assessment by PET/CT. J Nucl Med. 2004;45:266-271.

4. Biegon A, Alexoff DL, Kim SW, et al. Aromatase imaging with $\left[N\right.$-methyl- $\left.{ }^{11} \mathrm{C}\right]$ vorozole PET in healthy men and women. J Nucl Med. 2015;56:580-585.

5. Initiative to Reduce unnecessary radiation exposure from medical imaging. U.S. Food and Drug Administration website. https://www.fda.gov/radiation-emittingproducts/radiationsafety/radiationdosereduction/default.htm. Updated August 15, 2018. Accessed September 12, 2018.

6. The European ALARA Network. International Atomic Energy Agency website. http://www-ns.iaea.org/tech-areas/communication-networks/orpnet/ean.asp?s=2\&l=7. Updated January 15, 2016. Accessed September 12, 2018.

7. Conway JL, Connors JM, Tyldesley S, et al. Secondary breast cancer risk by radiation volume in women with Hodgkin lymphoma. Int J Radiat Oncol Biol Phys. 2017;97:35-41.

8. Kajihara M, Goto M, Hirayama Y, et al. Effect of the menstrual cycle on background parenchymal enhancement in breast MR imaging. Magn Reson Med Sci. 2013;12:39-45.

9. Mann RM, Balleyguier C, Baltzer PA, et al. Breast MRI: EUSOBI recommendations for women's information. Eur Radiol. 2015;25:3669-3678.

10. Clayton JA. Applying the new SABV (sex as a biological variable) policy to research and clinical care. Physiol Behav. 2018;187:2-5.

11. Grant EJ, Brenner A, Sugiyama H, et al. Solid cancer incidence among the Life Span Study of atomic bomb survivors: 1958-2009. Radiat Res. 2017;187:513-537. 